\title{
Article \\ Simulated Study of High-Sensitivity Gas Sensor with a Metal-PhC Nanocavity via Tamm Plasmon Polaritons
}

\author{
Liang Li (1) and Haoyue Hao * \\ School of Physics and Optoelectronic Engineering, Shandong University of Technology, Zibo 255000, China; \\ liangli@sdut.edu.cn \\ * Correspondence: haohao_yue@163.com
}

check for updates

Citation: Li, L.; Hao, H. Simulated Study of High-Sensitivity Gas Sensor with a Metal-PhC Nanocavity via Tamm Plasmon Polaritons. Photonics 2021, 8, 506. https://doi.org/ $10.3390 /$ photonics 8110506

Received: 22 September 2021 Accepted: 8 November 2021 Published: 10 November 2021

Publisher's Note: MDPI stays neutral with regard to jurisdictional claims in published maps and institutional affiliations.

Copyright: (c) 2021 by the authors. Licensee MDPI, Basel, Switzerland. This article is an open access article distributed under the terms and conditions of the Creative Commons Attribution (CC BY) license (https:// creativecommons.org/licenses/by/ $4.0 /)$.

\begin{abstract}
An optical configuration was designed and simulated with a metal-photonic crystal (PhC) nanocavity, which had high sensitivity on gas detection. The simulated results shows that this configuration can generate a strong photonic localization through exciting Tamm plasmon polaritons. The strong photonic localization highly increases the sensitivity of gas detection. Furthermore, this configuration can be tuned to sense gases at different conditions through an adjustment of the detection light wavelength, the period number of photonic crystal and the thickness of the gas cavity. The sensing routes to pressure variations of air were revealed. The simulation results showed that the detection precision of the proposed device for gas pressure could reach $0.0004 \mathrm{~atm}$.
\end{abstract}

Keywords: optical sensor; Tamm plasmon polaritons; optical Tamm state; gas refractive index

\section{Introduction}

A high-sensitivity method of gas sensing is increasingly necessary through the development of a measurement technique. Recently, optical sensors have played an important role in the high-sensitivity sensing of various targets due to the development of photonic and laser technologies [1-3]. Tamm plasmon polaritons (TPPs) based optical sensors present many advantages $[4,5]$. TPPs, traditionally formed at the interfaces between photonic crystal and metal film, can be excited with both transverse electric (TE) and transverse magnetic (TM) polarized lights without the assistance of external structures [6,7]. Meanwhile, TPPs can selectively transform the energy of a specific wavelength light into an electromagnetic mode and can generate optical field enhancement. Their easy excitation mode and high optical field localization make TPPs attractive for many types of research fields, including sensors [4,5,8], photodetection [9-11], thermal emission [12], solar cell [13,14], confined laser [15,16], nonlinear optical effects [17,18], perfect absorption [19,20], and tunable filters [21-23]. Benefiting from the increasingly mature preparation technology, simple Tamm structures have been experimentally studied and have garnered plenty of results that matched well with theoretical studies [24-29]. These results demonstrate the value and the potential of TPPs-based devices. Recently, we found that a metal-PhC cavity could also generate TPPs, as the cavity could be used as gas channel. In this work, we designed an optical sensor based on a Ag-PhC nanocavity, that could allow for the high-sensitivity detection of gas.

\section{Structure and Methods}

The structure of an $\mathrm{Ag}-\mathrm{PhC}$ nanocavity is shown in Figure 1a, and mainly contains $\mathrm{PhC}$, gas nanocavity and Ag film. The preparation of an Ag-PhC nanocavity can be processed as discussed. Firstly, by preparing Ag film on silica substrate and etching a gas nanocavity on the Ag film. Then, by preparing a PhC structure on another silica substrate. Finally, by combining the etched $\mathrm{Ag}$ film and the PhC structure. The selected alternate dielectric layers of the $\mathrm{PhC}$ structure are silicon dioxide $\left(\mathrm{SiO}_{2}\right)$ and titanium dioxide $\left(\mathrm{TiO}_{2}\right)$, 
two common periodic structure materials. The thicknesses of $\mathrm{SiO}_{2}$ and $\mathrm{TiO}_{2}$ are set as $245 \mathrm{~nm}$ and $160 \mathrm{~nm}$, respectively. The thickness of the gas nanocavity is set as $50 \mathrm{~nm}$.

(a)

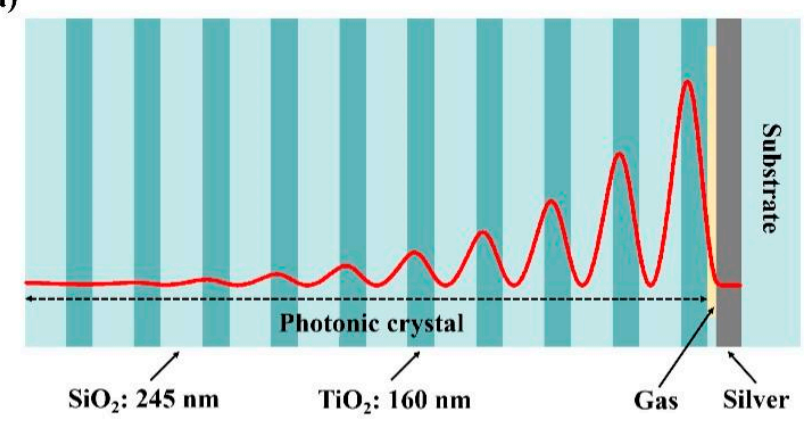

(b)

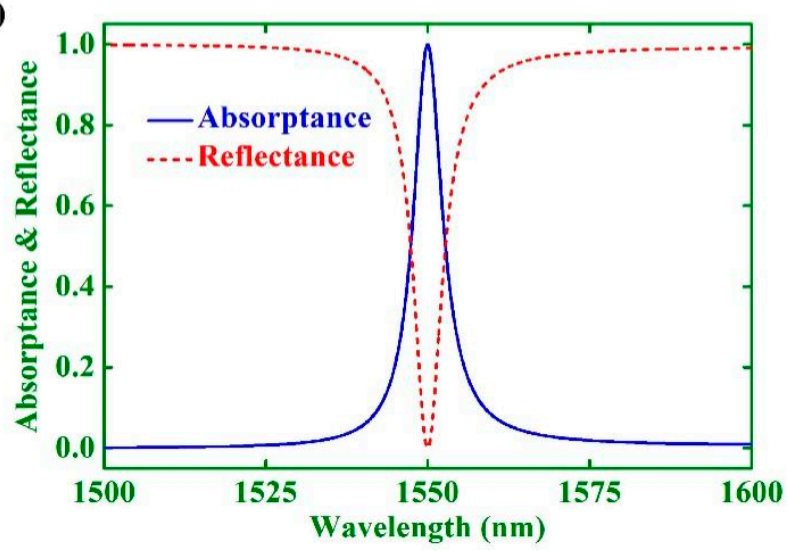

Figure 1. (a) Schematic of the Ag-PhC nanocavity. Red line is the electric field distribution of light at $1550 \mathrm{~nm}$ (b) Absorption and reflection spectra of the Ag-PhC nanocavity when the period number of $\mathrm{PhC}$ is 10 .

Both the reflection and absorption spectra of this configuration are theoretically investigated by the transfer matrix approach. There are two different matrices in this method, which are the transmission matrix (TM) and propagation matrix (PM), that can be described as:

$$
T M_{k}=\frac{1}{t_{k}}\left[\begin{array}{cc}
1 & r_{k} \\
r_{k} & 1
\end{array}\right], P M_{k}=\left[\begin{array}{cc}
\exp \left(-i \varphi_{k}\right) & 0 \\
0 & \exp \left(-i \varphi_{k}\right)
\end{array}\right] .
$$

Here, $t_{k}$ and $r_{k}$ are the transmission and reflection coefficients of light transmission from the $(k-1)$-th layer to the $k$-th layer. $\varphi_{k}$ is the phase of light propagating in the $k$-th layer. Thus, the total transfer matrix can be represented as:

$$
M=T M_{1} P M_{1} \cdots T M_{20} P M_{20} T M_{g} P M_{g} T M_{s} .
$$

Here, $T M_{g}$ refers the transmission matrix for the interface of the $\mathrm{TiO}_{2}$ layer and the gas nanocavity, $P M_{g}$ refers the propagation matrix of the gas nanocavity, $T M_{S}$ refers the transfer matrix for the interface of the gas nanocavity and the Ag film. The transmission intensity will increase when the thickness of the Ag film is thinner than $60 \mathrm{~nm}$. This will influence the intensity of the reflection light. In this study, the thickness of Ag film is set as $150 \mathrm{~nm}$. Thus, the transmittance of the $\mathrm{Ag}-\mathrm{PhC}$ nanocavity is near zero and negligible. The reflectance and absorptance of the structure can be expressed as $R=\left|M_{21} / M_{11}\right|^{2}$ and $A=1-R . M_{21}$ refers the first matrix element in the second row of $M . M_{11}$ refers the first matrix element in the first row of $M$.

Figure $1 \mathrm{~b}$ shows the reflection and absorption spectra of the $\mathrm{Ag}$-PhC nanocavity when the period number of $\mathrm{PhC}$ is set as 10. The refractive indices of $\mathrm{SiO}_{2}$ and $\mathrm{TiO}_{2}$ can be set 
as 1.45 and 2.13 [23]. The permittivity of the Ag film is described by the Lorentz-Drude model [30]. It can be seen that the proposed structure has a narrow-band absorption of almost $1550 \mathrm{~nm}$. The reflection spectrum shows a narrow valley at the corresponding wavelength. Meanwhile, the red line in Figure 1a shows the electric field distribution of light at $1550 \mathrm{~nm}$, at which a high localization in the PhC exists. These results reveal the generation of TPPs in the Ag-PhC nanocavity.

\section{Results and Discussion}

The intensity of the reflection light $(I)$ and the intensity of the light source $\left(I_{0}\right)$ can be detected using an optical power meter. We can simulate $I / I_{0}$ by calculating the reflectance of the $\mathrm{Ag}-\mathrm{PhC}$ nanocavity. The influence of the gas refractive index $(n)$ on the reflectance of the $\mathrm{Ag}-\mathrm{PhC}$ nanocavity is shown in Figure 2, in which the period number of the $\mathrm{PhC}$ $(N)$ is set as 10. As shown in Figure 2a, we can find that the reflection valley blue-shifts from $\sim 1552 \mathrm{~nm}$ to $\sim 1548 \mathrm{~nm}$ as $n$ varies from 0.97 to 1.03 . We derived the reflectance of the Ag-PhC nanocavity at $1548 \mathrm{~nm}, 1550 \mathrm{~nm}$ and $1552 \mathrm{~nm}$, as shown in Figure 2b-d. It can be observed that the reflection has high selectivity on the light wavelength. For $1548 \mathrm{~nm}$ light, the reflectance decreases from $\sim 0.7$ to near zero as $n$ varies from 0.97 to 1.03 , which increases from almost zero to $\sim 0.7$ for $1552 \mathrm{~nm}$ light. To clearly study the sensitivity to $n$, we plotted the derivative of the reflection with $n$, as the dotted lines in Figure $2 \mathrm{~b}-\mathrm{d}$. It can be observed that the absolute value of derivation reaches $\sim 15$, which means the reflectance of the $\mathrm{Ag}-\mathrm{PhC}$ nanocavity will change by $\sim 15$ times the $I_{0}$ as $n$ changes 1 . The maximum absolute value of derivation appeared at a medium value of the reflectance, which is disparate for different light wavelengths. That means we can tune the sensitivity of gas nanocavity by selecting the wavelength of light source.
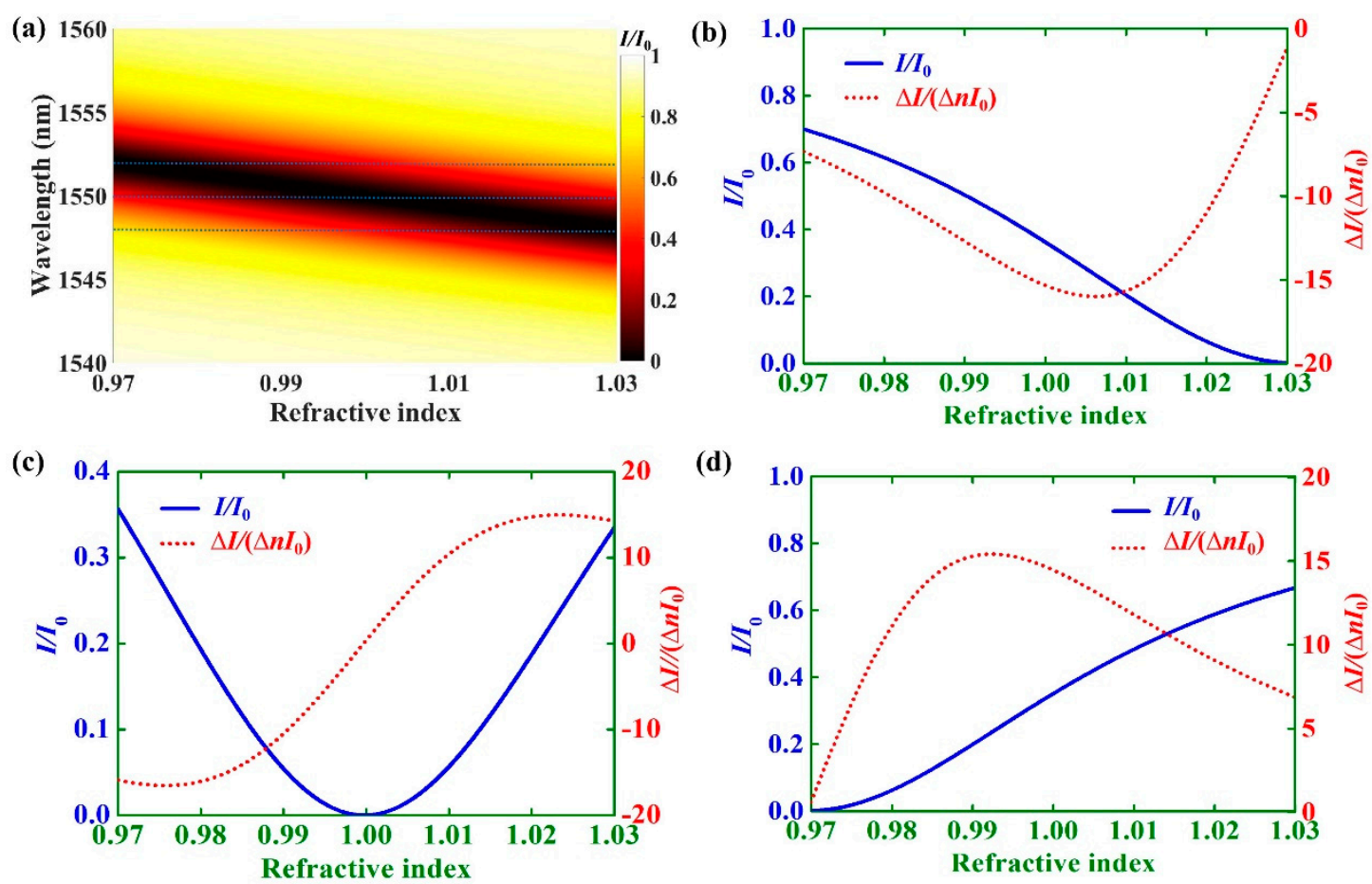

Figure 2. (a) Evolution of the reflection spectrum for the Ag-PhC nanocavity with different refractive index of gas. Reflection and the derivative of reflection with $n$ at (b) $1448 \mathrm{~nm},(\mathbf{c}) 1550 \mathrm{~nm}$ and (d) $1552 \mathrm{~nm}$.

After this, we investigated the influence of $N$ (the period number of $\mathrm{PhC}$ ), as shown in Figure 3. The wavelength of the light source is set as $1550 \mathrm{~nm}$. It can be observed that the minimum value of reflectance is lowest when $N$ is 10 , which is near zero. This minimum value of reflectance appears at a lower $n$ as $N$ increases. Meanwhile, we calcu- 
lated the derivation of lines in Figure 3a, as shown in Figure 3b. It can be seen that the maximum value of derivation increases with an increase of $N$. Meanwhile, the position of this maximum sensitivity appeared at different $n$ for different $N$. These results reveal that the sensitivity of the Ag-PhC nanocavity on the gas nanocavity can be adjusted using the period number of $\mathrm{PhC}$.
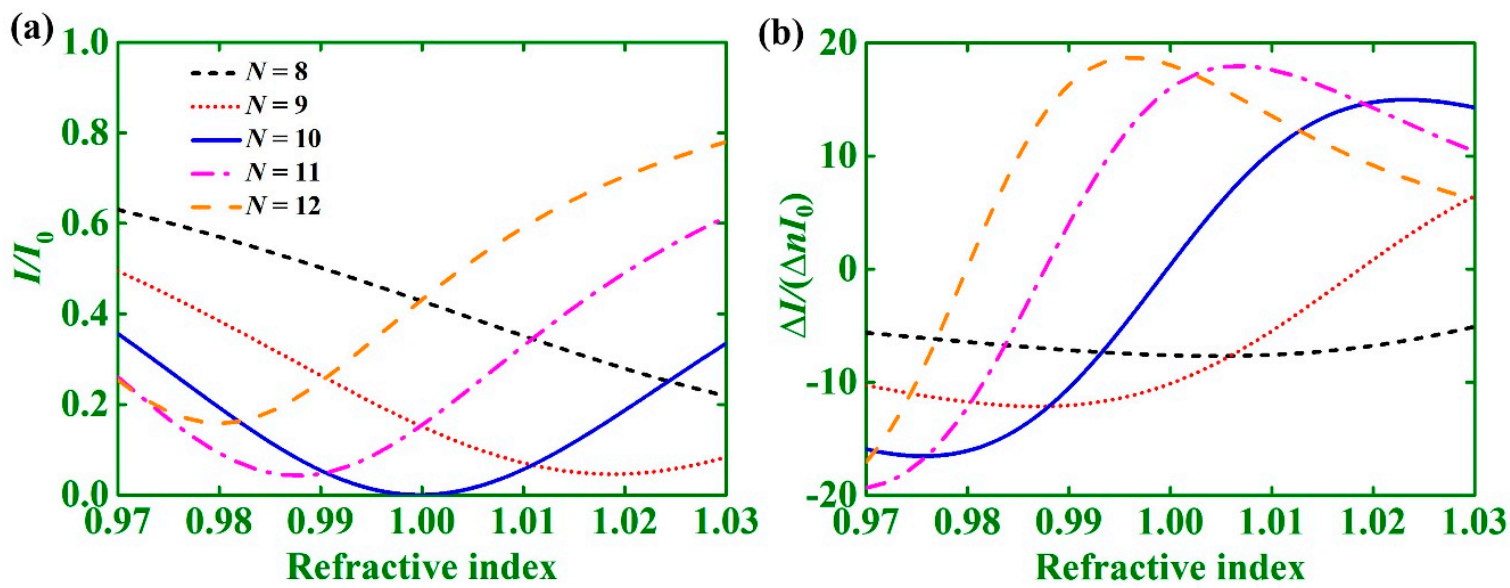

Figure 3. Dependence of (a) the reflection and (b) the derivative of reflection on gas refractive index at different $N$. The light wavelength is set as $1550 \mathrm{~nm}$.

Furthermore, the influence of the thickness of the nanocavity $\left(d_{g}\right)$ was investigated. We found a series of $d_{g}$ could lead to the TPPs reflectance valley at $1550 \mathrm{~nm}$, such as $50 \mathrm{~nm}, 825 \mathrm{~nm}, 1600 \mathrm{~nm}, 2375 \mathrm{~nm}$ and so on. These thicknesses of the nanocavity satisfy $n_{g} \cdot \Delta d_{g}=\lambda / 2$. Furthermore, $n_{g}$ refers the refractive index of the cavity. $\lambda$ refers the wavelength of light. The generation of TPPs must satisfy the phase matching condition that can be deduced as [6,7]:

$$
r_{\mathrm{PhC}} r_{\mathrm{Ag}} \exp \left(2 i \varphi_{g}\right)=1
$$

Here, $r_{\mathrm{PhC}}$ and $r_{\mathrm{Ag}}$ refer the reflection coefficients from the gas cavity to the $\mathrm{PhC}$ and the Ag layer, respectively. $\varphi_{g}=2 \pi n_{g} d_{g} / \lambda$ is the phase of light propagating in the gas cavity. As seen in Equation (4), the variation of $\varphi_{g}$ needs to be an integral number of $\pi$, which corresponds well with the above results. The influence of $d_{g}$ on the reflectance spectrum is investigated, as shown in Figure 4a. It can be found that the full width of half maximum (FWHM) of the TPPs valley becomes narrower with an increase of $d_{g}$. The FWHM of the TPPs valley is $5.38 \mathrm{~nm}\left(d_{g}=50 \mathrm{~nm}\right), 3.14 \mathrm{~nm}\left(d_{g}=825 \mathrm{~nm}\right), 2.22 \mathrm{~nm}\left(d_{g}=1600 \mathrm{~nm}\right)$, $1.71 \mathrm{~nm}\left(d_{g}=2375 \mathrm{~nm}\right)$, respectively. Additionally, the derivative of reflection on the gas refractive index is also investigated, as shown in Figure $4 \mathrm{~b}$. It can be seen that the maximum value of derivation dramatically increases with an increasing $d_{g}$, which reaches $\sim 800$ for $d_{g}=2375 \mathrm{~nm}$. However, the detection range of the gas refractive index decreases with an increase of $d_{g}$. We can set the monotone increasing section in Figure $4 \mathrm{~b}$ as the detection range. For $d_{g}=50 \mathrm{~nm}$, the detection range is $\sim 0.04$. For $d_{g}=2375 \mathrm{~nm}$, the detection range decreases to $\sim 0.0001$. Thus, we can select the applicable thickness of the gas cavity based on practical necessity.

To discuss the detection precision of the proposed structure, we calculated the wavelength of the reflectance valley at different $d_{g}$. From Figure 5, we found that the wavelength of the reflectance valley linearly red-shifts when the refractive index of the gas cavity increases. For the proposed structure, the detection sensitivity can be set as $S=\Delta \lambda / \Delta n$. It can be deduced that $S$ reaches $1057 \mathrm{~nm} /$ RIU when $d_{g}=2375 \mathrm{~nm}$. The figure of merit (FOM) is also an important parameter to characterize the sensing ability, which can be defined as FOM $=S / F W H M$. It can be deduced that FOM reaches 618.1/RIU when $d_{g}=2375 \mathrm{~nm}$. These parameters of detection sensitivity can be further enhanced by increasing the thickness of the gas cavity. This can be explained by the phase matching condition, for which 
the TPPs wavelength is related to $\varphi_{g}$. The refractive index of the gas will have a greater influence on $\varphi_{g}$ when the thickness of the gas cavity increases. To assess the detection ability of the proposed configuration, sensitivities of different TPP-based gas sensors are listed in Table 1. It can be seen that the proposed structure in this paper has a relatively high sensitivity on the refractive index of gas.
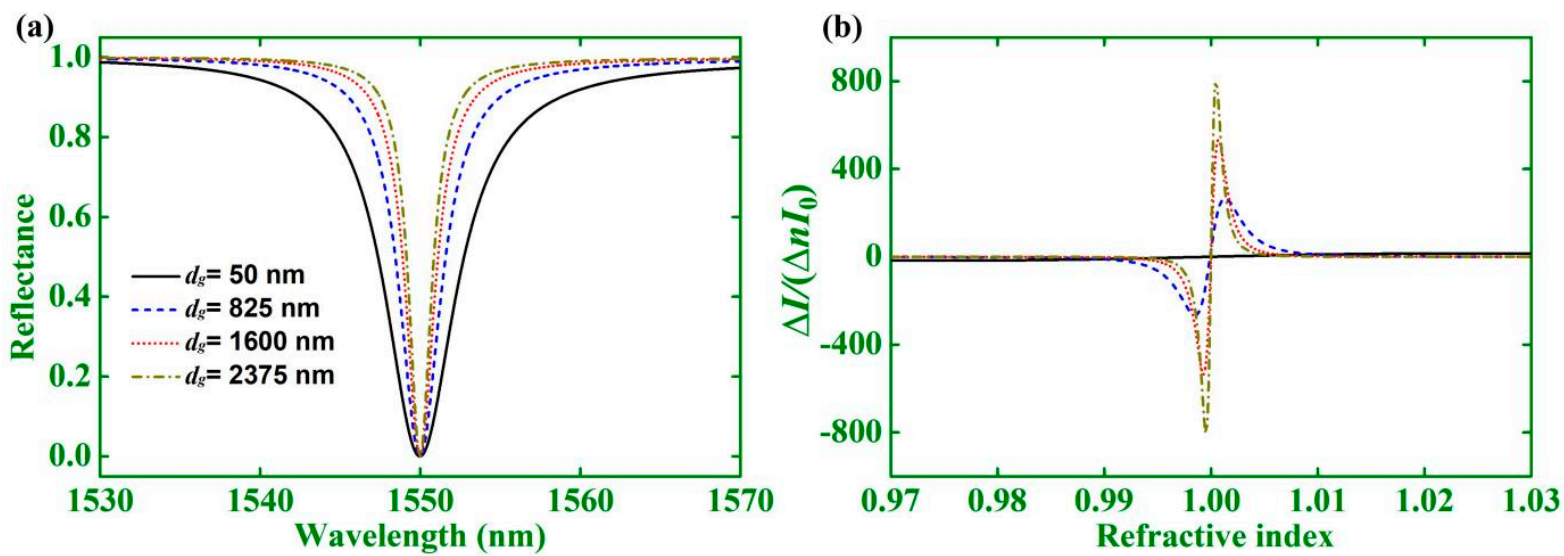

Figure 4. (a) Reflectance spectrum of the proposed structure with different $d_{g}$. (b) Dependence of the derivative of reflection on gas refractive index at $1550 \mathrm{~nm}$ with different $d_{g}$.

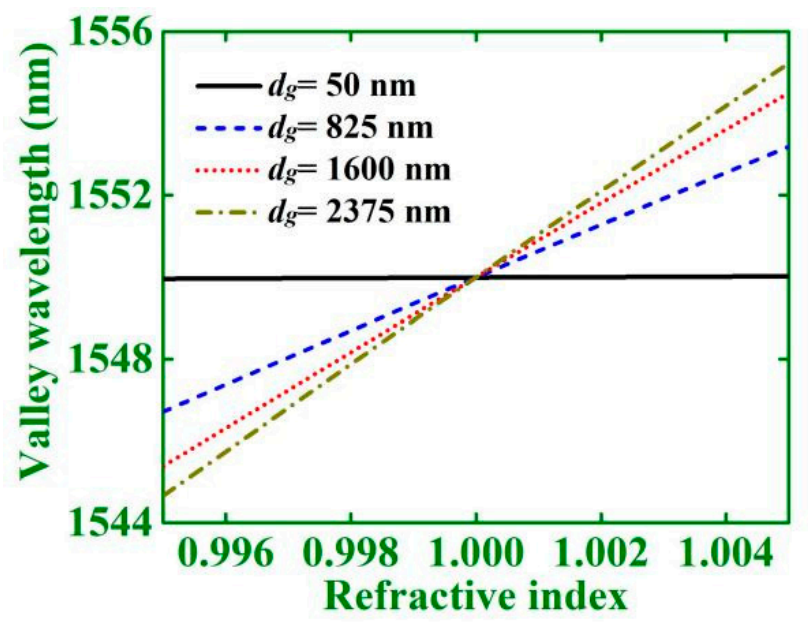

Figure 5. Dependence of the TPPs valley wavelength on gas refractive index at different $d_{g}$.

Table 1. Sensitivities of different Tamm plasmon based gas sensors.

\begin{tabular}{ccc}
\hline Structure & $S$ (nm/RIU) & FOM (/RIU) \\
\hline PhC-Au-Gas [31] & 55 & - \\
Ag-Gas/Si PhC [4] & 83.3 & - \\
Graphene-Gas-PhC [32] & & 142 \\
(in terahertz band) & - & 618.1 \\
\hline This work & 1057 & \\
\hline
\end{tabular}

\section{Simulation Sensing of Gas Pressure}

To clearly demonstrate the high sensitivity of the $\mathrm{Ag}-\mathrm{PhC}$ nanocavity on gas, we simulated the detection of air at different gas pressures. The sensing route is shown in Figure 6a. The $1550 \mathrm{~nm}$ laser passes through a splitter into the Ag-PhC nanocavity. The reflection laser of the $\mathrm{Ag}-\mathrm{PhC}$ nanocavity is reflected by the splitter. Finally, the laser reflected from the splitter is detected by an optical detector, which can obtain the intensity of signal light $I$. The gas cavity is exposed to the outside, in which the gas pressure is 
consistent with the environment. The relationship between gas pressure and the gas refractive index can be expressed as [33]:

$$
n=1+\frac{p\left(n_{0}-1\right)}{96095.43} \times \frac{1+p(0.613-0.00998 t) \times 10^{-8}}{1+0.003661 t}
$$

(a)

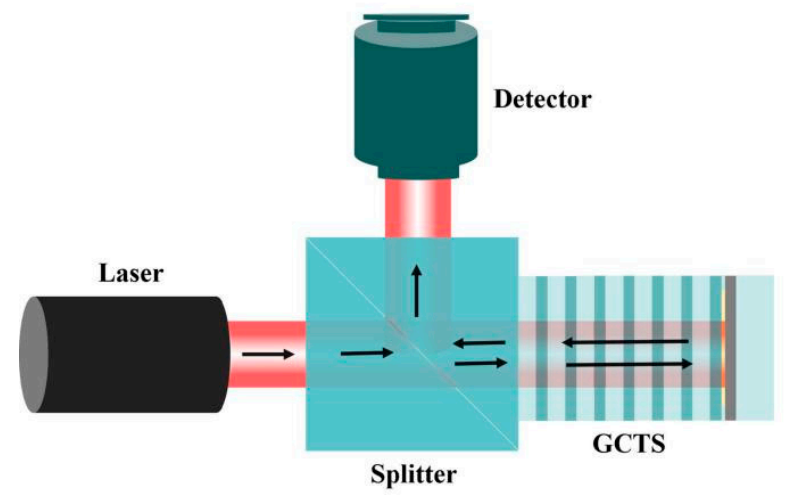

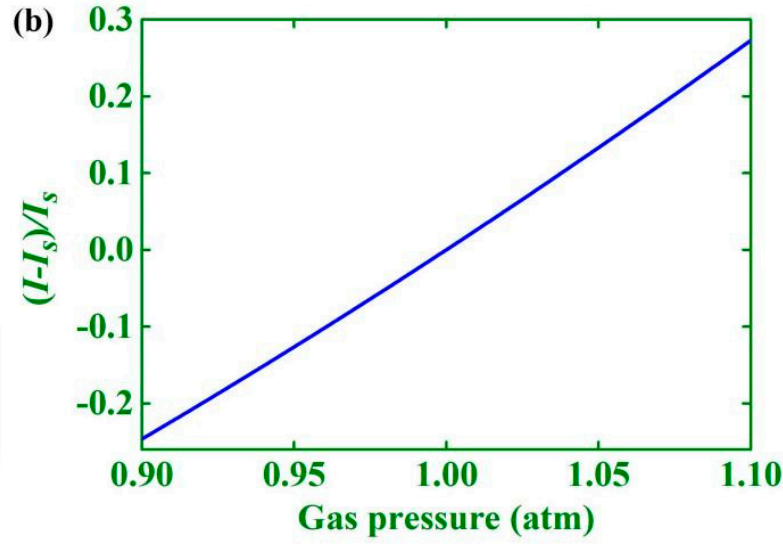

Figure 6. (a) Schematic of the proposed configuration for measuring gas pressure (b) The relation between normalized light intensity variation and gas pressure. $d_{g}$ is set as $2375 \mathrm{~nm}$.

Here, $n$ is the gas refractive index and $n_{0}$ is the gas refractive index of standard air, which equals 1.00012438 for $1550 \mathrm{~nm}$ light. $p$ is the gas pressure and $t$ is the temperature.

We set a standard intensity of the signal light $I_{S}$ at $1.0 \mathrm{~atm}$ and $25^{\circ} \mathrm{C}$. Based on the above formula, we plotted the intensity variation of the signal light (normalized by $I_{s}$ ) with different gas pressures as shown in Figure $6 \mathrm{~b}$. It can be seen that $I$ is greatly influenced by the gas pressure, has and that they have a significant linear relationship. The variation rate of normalized light intensity on gas pressure reaches $\sim 2.5$ per atm, which means that $\Delta p I / \Delta I$ is $\sim 0.4 \mathrm{~atm}$ if we set the detection precision of optical power meter as a thousandth of the detection range. Thus, the detection precision of gas pressure can reach $0.0004 \mathrm{~atm}$.

\section{Conclusions}

In summary, TPPs were generated in an Ag-PhC nanocavity. Based on the Ag-PhC nanocavity, an optical sensor for gas was designed. The simulated results revealed that the detection sensitivity for the gas refractive index could reach $1057 \mathrm{~nm}$ and the FOM is able to reach 618.1/RIU. Meanwhile, the simulated results demonstrated that the detection precision of the $\mathrm{Ag}-\mathrm{PhC}$ nanocavity on gas pressure could reach $0.0004 \mathrm{~atm}$. The proposed configuration can also be used for many other applications, such as concentration sensing and composition detecting.

Author Contributions: Conceptualization, L.L.; methodology, L.L.; software, L.L.; validation, L.L.; formal analysis, H.H.; investigation, L.L.; resources, L.L.; data curation, H.H.; writing—original draft preparation, L.L.; writing-review and editing, H.H.; visualization, H.H.; supervision, L.L.; project administration, L.L. and H.H.; funding acquisition, L.L. and H.H. All authors have read and agreed to the published version of the manuscript.

Funding: This work was supported by National Natural Science Foundation of China (project No. 12004217); Natural Science Foundation of Shandong Province (project Nos. ZR201910230199, ZR201910230202).

Data Availability Statement: All relevant data is within the present manuscript.

Conflicts of Interest: The authors declare that they have no known competing financial interest or personal relationships that could have appeared to influence the work reported in this paper. 


\section{References}

1. Zhou, J.; Wang, Y.; Liao, C.; Sun, B.; He, J.; Yin, G.; Liu, S.; Li, Z.; Wang, G.; Zhong, X.; et al. Liquid-crystal active Tamm-plasmon devices. Sens. Actuators B-Chem. 2015, 208, 315-319. [CrossRef]

2. Motogaito, A.; Ito, Y. Excitation mechanism of surface plasmon polaritons for surface plasmon sensor with $1 \mathrm{D}$ metal grating structure for high refractive index medium. Photonic Sens. 2019, 9, 11-18. [CrossRef]

3. Kim, K.J.; Lu, P.; Culp, J.T.; Ohodnicki, P.R. Metal-organic framework thin film coated optical fiber sensors: A novel waveguidebased chemical sensing platform. ACS Sens. 2018, 3, 386-394. [CrossRef]

4. Zhang, W.; Wang, F.; Rao, Y.; Jiang, Y. Novel sensing concept based on optical Tamm plasmon. Opt. Express 2014, 22, 14524-14529. [CrossRef]

5. Li, N.; Tang, T.; Li, J.; Luo, L.; Sun, P.; Yao, J. Highly sensitive sensors of fluid detection based on magneto-optical optical Tamm state. Sens. Actuators B-Chem. 2018, 265, 644-651. [CrossRef]

6. Kaliteevski, M.; Iorsh, I.; Brand, S.; Abram, R.A.; Chamberlain, J.M.; Kavokin, A.V.; Shelykh, I.A. Tamm plasmon-polaritons: Possible electromagnetic states at the interface of a metal and a dielectric Bragg mirror. Phys. Rev. B 2007, 76, 165415. [CrossRef]

7. Sasin, M.E.; Seisyan, R.P.; Kalitteevski, M.A.; Brand, S.; Abram, R.A.; Chamberlain, J.M.; Egorov, A.Y.; Vasilev, A.P.; Mikhrin, V.S.; Kavokin, A.V. Tamm plasmon polaritons: Slow and spatially compact light. Appl. Phys. Lett. 2008, 92, 251112. [CrossRef]

8. Zaky, Z.A.; Ahmed, A.M.; Shalaby, A.S.; Aly, A.H. Refractive index gas sensor based on the Tamm state in a one-dimensional photonic crystal: Theoretical optimisation. Sci. Rep. 2020, 10, 9736. [CrossRef] [PubMed]

9. Wang, J.; Zhu, Y.; Wang, W.; Li, Y.; Gao, R.; Yu, P.; Xu, H.; Wang, Z. Broadband Tamm plasmon-enhanced planar hot-electron photodetector. Nanoscale 2020, 12, 23945-23952. [CrossRef] [PubMed]

10. Zhu, Y.; Yu, P.; Liu, T.; Xu, H.; Govorov, A.O.; Wang, Z. Nanolayered Tamm plasmon-based multicolor hot electron photodetection for O- and C-band telecommunication. ACS Appl. Electron. Mater. 2021, 3, 639-650. [CrossRef]

11. Zhu, Y.; Xu, H.; Yu, P.; Wang, Z. Engineering plasmonic hot carrier dynamics toward efficient photodetecion. Appl. Phys. Rev. 2021, 8, 021305. [CrossRef]

12. Wang, Z.; Clark, J.K.; Ho, Y.L.; Vilquin, B.; Daiguji, H.; Delaunay, J.J. Narrowband thermal emission realized through the coupling of cavity and Tamm plasmon resonances. ACS Photonics 2018, 5, 2446-2452. [CrossRef]

13. Zhang, X.L.; Song, J.F.; Li, X.B.; Feng, J.; Sun, H.B. Optical Tamm states enhanced broad-band absorption of organic solar cells. Appl. Phys. Lett. 2012, 101, 243901. [CrossRef]

14. Bikbaev, R.G.; Vetrov, S.Y.; Timofeev, I.V.; Shabanov, V.F. Photosensitivity and reflectivity of the active layer in a Tamm-plasmonpolariton-based organic solar cell. Appl. Opt. 2021, 60, 3338-3343. [CrossRef]

15. Symond, C.; Lheureux, G.; Hugonin, J.P.; Greffet, J.J.; Laverdant, J.; Brucoli, G.; Lemaitre, A.; Senellart, P.; Bellessa, J. Confined Tamm plasmon lasers. Nano Lett. 2013, 13, 3179-3184. [CrossRef]

16. Toanen, V.; Symonds, C.; Benoit, J.M.; Gassenq, A.; Lemaitre, A.; Bellessa, J. Room-temperature lasing in a low-loss Tamm plasmon cavity. ACS Photonics 2020, 7, 2952-2957. [CrossRef]

17. Lee, K.J.; Wu, J.W.; Kim, K. Enhanced nonlinear optical effects due to the excitation of optical Tamm plasmon polaritons in one-dimensional photonic crystal structures. Opt. Express 2013, 21, 28817-28823. [CrossRef] [PubMed]

18. Xue, C.; Jiang, H.; Lu, H.; Du, G.; Chen, H. All-optical bistable logic control based on coupled Tamm plasmons. Opt. Lett. 2013, 38, 4092-4095.

19. Gong, Y.; Liu, X.; Lu, H.; Wang, L.; Wang, G. Perfect absorber supported by optical Tamm states in plasmonic waveguide. Opt. Express 2011, 19, 18393-18398. [CrossRef] [PubMed]

20. Li, L.; Zhao, H.; Zhang, J. Tunable perfect absorber supported by accumulation electron gas at ITO-dielectric heterointerface. J. Phys. D Appl. Phys. 2017, 50, 405109. [CrossRef]

21. Lu, H.; Gan, X.; Jia, B.; Mao, D.; Zhao, J. Tunable high-efficiency light absorption of monolayer graphene via Tamm plasmon polaritons. Opt. Lett. 2016, 41, 4743-4746. [CrossRef]

22. Wang, X.; Jiang, X.; You, Q.; Guo, J.; Dai, X.; Xiang, Y. Tunable and multichannel terahertz perfect absorber due to Tamm surface plasmons with graphene. Photonics Res. 2017, 5, 536-542. [CrossRef]

23. Li, L.; Zhao, H.; Zhang, J. Electrically tuning reflection of graphene-based Tamm plasmon polariton structures at $1550 \mathrm{~nm}$. Appl. Phys. Lett. 2017, 111, 083504. [CrossRef]

24. Nunez-Sanchez, S.; Lopez-Garcia, M.; Murshidy, M.M.; Abdel-Hady, A.G.; Serry, M.; Adawi, A.M.; Rarity, J.G.; Oulton, R.; Barnes, W.L. Excitonic optical Tamm states: A step toward a full molecular-dielectric photonic integration. ACS Photonics 2016, 3, 743-748. [CrossRef]

25. Mischok, A.; Siegmund, B.; Ghosh, D.S.; Benduhn, J.; Spoltore, D.; Bohm, M.; Frob, H.; Korner, C.; Leo, K.; Vandewal, K. Controlling Tamm plasmons for organic narrowband near-infrared photodetectors. ACS Photonics 2017, 4, 2228-2234. [CrossRef]

26. Yang, Z.; Ishii, S.; Yokoyama, T.; Dao, T.D.; Sun, M.; Pankin, P.S.; Timofeev, I.V.; Nagao, T.; Chen, K. Narrowband wavelength selective thermal emitters by confined Tamm plasmon polaritons. ACS Photonics 2017, 4, 2212-2219. [CrossRef]

27. Zhang, C.; Wu, K.; Giannini, V.; Li, X. Planar hot-electron photodetection with Tamm plasmons. ACS Nano 2017, 11, 1719-1727. [CrossRef]

28. Cheng, H.; Kuo, C.; Hung, Y.; Chen, K.; Jeng, S. Liquid-crystal active Tamm-plasmon devices. Phys. Rev. Appl. 2018, 9, 064034. [CrossRef] 
29. Tsurimaki, Y.; Tong, J.K.; Boriskin, V.N.; Semenov, A.; Ayzatsky, M.I.; Machekhin, Y.P.; Chen, G.; Boriskina, S.V. Topological engineering of interfacial optical Tamm states for highly sensitive near-singular-phase optical detection. ACS Photonics 2018, 5, 929-938. [CrossRef]

30. Rakic, A.D.; Djurisic, A.B.; Elazar, J.M.; Majewski, M.L. Optical properties of metallic films for vertical-cavity optoelectronic devices. Appl. Opt. 1998, 37, 5271-5283. [CrossRef]

31. Anguie, B.; Fuertes, M.C.; Angelome, P.C.; Abdala, N.L.; Soler Illia, G.J.A.A.; Fainstein, A. Tamm plasmon resonance in mesoporous multilayers: Toward a sensing application. ACS Photonics 2014, 1, 775-780.

32. Keshavarz, M.M.; Alighanbari, A. Self-referenced terahertz refractive index sensor based on a cavity resonance and Tamm plasmon modes. Appl. Opt. 2020, 59, 4517-4526. [CrossRef] [PubMed]

33. Edlén, B. The refractive index of air. Metrologia 2005, 2, 71. [CrossRef] 